\title{
A IMPORTÂNCIA DA DIDÁTICA DOCENTE NOS CURSOS DE PEDAGOGIA
}

Gabriela de Proença dos Santos

Pedagoga e Orientadora educacional Rede Pública Municipal de Santos

\section{RESUMO}

Este estudo tem por objetivo discutir e ressaltar a didática como recurso e elemento fundamental para a eficácia e adequação à novos contextos de ensino-aprendizagem nos cursos de Pedagogia. A metodologia adotada trata-se de pesquisa qualitativa, a partir de revisão bibliográfica, que embasou a discussão do tema. Após análise de conteúdo das literaturas, ficou claro a importância da didática na contribuição da formação docente sob a ótica das mudanças pelas quais a educação vem passando ao longo dos anos quanto à formação e o papel do docente universitário.

\section{Palavras-Chave: Didática, Prática pedagógica, Pedagogia}




\section{1- INTRODUÇÃO}

Educação e escola estão presentes na sociedade desde os temos antigos. Isso denota que as relações no processo educativo também remotam a essa época. Não é recente a relação professor-aluno assim como não é nova a forma como essa relação se desenvolve.

A construção do conhecimento pode acontecer de diversas formas, assim como a utilização dos mesmos. Neste ponto, para que tudo ocorra sem ruídos, favorecendo uma boa comunicação, surge a didática como elo essencial nesse processo.

Ela é preponderante para qualquer estratégia de gestão do conhecimento porque trata das experiências, conceitos e formas para visualizar caminhos para o ensino.

No entanto, embora atualmente a disseminação da informação a respeito de estratégias didáticas para o ensino esteja em evidência, muitos professores universitários apresentam deficiências quanto aos aspectos ligados à didática. Deficiências estas relacionadas a inúmeras motivações de cunho pessoal ou profissional.

Um ponto a ser discutido é a complexidade da formação, quais são as metas a serem alcançadas e meios necessários para uma aprendizagem plena. Nesse contexto, coloca-se a seguinte questão: Qual é o papel da didática para o professor do curso de Pedagogia na atualidade?

Este artigo tem por objetivo ressaltar a importância da didática para o professor do ensino superior no processo de ensino aprendizagem na sala de aula. Entendendo, dessa forma, que ela é um aspecto fundamental na construção do conhecimento acadêmico tanto para docentes quanto para os alunos.

As universidades necessitam dispor de habilidades pedagógicas que tornem o aprendizado eficaz.

O artigo foi organizado por meio de revisão bibliográfica de fontes que referenciavam o tema. No primeiro momento, considerará a didática como determinante dos passos que o pedagogo percorrerá, para que este saiba como proceder em relação ao ensino-aprendizagem de seu aluno. Depois, o embasamento na didática para a formação acadêmica, para elaborar estratégias na tentativa de solucionar os problemas educacionais e adequar-se às modificações da educação com desenvoltura.

\section{2- DIDÁTICA}

\section{2-1 DIDÁTICA: DIRECIONANDO A APRENDIZAGEM}

Atualmente, é imprescindível haver algumas mudanças para que o ensino possa se adequar ao novo contexto que se apresenta bastante exigente, como a necessidade de adequação quanto a Base Nacional Comum Curricular. Se a didática não for bem estabelecida, o ensino não definirá as diretrizes dos novos pedagogos e estes não saberão como agir com os alunos. "É preciso introduzir, em cada momento, as ações que se adaptem às novas necessidades 
informativas que surgem constantemente" (ZABALA, 1998 p.51). A didática deve ser encarada para a licenciatura como uma fonte potencial para o aumento da eficácia da prática docente.

Nos últimos anos tenho desenvolvido o ensino da didática nos cursos de licenciatura e realizado pesquisas sobre formação inicial e contínua de professores. É a partir dessas experiências que exponho algumas reflexões, com o desafio de colaborar para a formação de professores. Nos cursos de formação inicial, tenho utilizado a produção de pesquisas em didática a serviço da reflexão dos alunos e da constituição de suas identidades como professores. Ao mesmo tempo, problematizando-as diante da realidade do ensino nas escolas, procuro desenvolver nos alunos uma atitude investigativa. Nesse contexto, estamos empenhados em ressignificar os processos formativos a partir da reconsideração dos saberes necessários à docência, colocando a prática pedagógica e docente escolar como objetivo de análise (PIMENTA, 1996).

Quando se fala em didática pensa-se logo em estratégias, ações e reflexão. Contudo, quem irá determinar sua utilização com eficiência será o professor. Este, precisa centrar na promoção do aprendizado, que representa o diferencial, constituindo a competência fundamental para os alunos, assumindo seu papel de "interlocutor mais experiente" (VEIGA, 1996).

A tendência é investir na didática, na qualificação dos pedagogos, que atuam em diversos níveis e modalidades do processo educativo, para que eles possam conduzir com valor agregado sua também função de professor, quando se formarem. Para que seu potencial possa ser utilizado com mais eficácia.

Durante muito tempo, acreditou-se que o ensino poderia ser bem desenvolvido com enfoque no professor, em seu conhecimento, "em que a importância do ensinar predominou sobre o aprender" (PIMENTA,1999). Mas, hoje, a realidade é outra: para que se possa desenvolver a aprendizagem, esta não pode estar dissociada do ensino.

Assim, torna-se fundamental refletir sobre o processo ensino-aprendizagem, sendo necessário também a conscientização sobre o conhecimento. É necessário e urgente formar organizações de aprendizagem, nas quais os estudantes de pedagogia e futuros professores, aprimorarão continuamente suas capacidades, trabalhando juntos na busca de inovações.

A formação não se restringe ao conhecimento do professor. Na verdade, é muito mais que isso: as diretrizes constantes na Lei de Diretrizes e Bases da Educação Nacional (LDB 9394/96) enfatizam as competências acima das disciplinas/conteúdos abrindo possibilidades para a prática do ensino, deixando de lado o conhecimento pedagógico abstrato (BRASIL, 2018).

Nisso, reside a importância de mudar o perfil desses cursos e adoção de um trabalho bem feito, iniciando um processo de discussões sobre as diretrizes curriculares atreladas à prática pedagógica, pois são esses pedagogos que irão recuperar o nível do ensino-aprendizagem para redução e/ou erradicação do fracasso escolar. Para isso, o profissional precisa ser proativo, tendo uma visão de aprendizagem como um todo. 
A formação e capacitação são primordiais quando se analisa o contexto do conhecimento e aprendizagem pela ótica da didática, pois todo o processo de aprendizagem está direcionado nas formas de realização do ensino, são elas que irão garantir que se aprenda a aprender.

Pensar o ensino e aprendizagem em termos da relação pedagógica implica em admitir a complexidade da situação da sala de aula e considerar as questões de ensino de um ponto de vista dinâmico (CORDEIRO, 2009, p.98).

O contexto atual, gerou consequências grandiosas na educação, determinando, por conseguinte, mudanças no comportamento e cultura de "ensinagem". Os alunos, que representam a condição indispensável nesse contexto, têm cada vez mais papel fundamental nos resultados das instituições educacionais, o motivo de tanta demanda, como visto nos últimos tempos.

Por isso, é urgente que, tanto cursos de pedagogia quanto professores sejam dinâmicos para acompanhar os processos e demandas dos alunos. Isso inclui trabalhar, na maior qualidade possível, com o perfil idealizado de um profissional preparado para atender os mais diversos propósitos na sua prática. Evidentemente orientando e avaliando-os durante esse caminho de formação.

\section{2-2 MUDANÇA E DINÂMICA DIDÁTICA}

A mudança de paradigma pode ser um fator determinante para a renovação da didática e sua adequação ao ensino atual, pois, com o movimento social concreto, no qual se atinge seus objetivos quando se transforma numa organização institucionalizada, nesse caso, a universidade, tornou-se imprescindível. Contudo, para ser benéfica, o professor precisa ampliar seu território de ação.

No entanto, para reformular a estrutura educacional e adequá-la como o contexto social exige, os cursos de pedagogia necessitam implementar modelos de formação de seus professores. Esse repensar de práticas deve considerar alguns fatores que até pouco tempo não possuíam importância para a educação, como o papel determinante da didática do professor, o conhecimento agregado às habilidades individuais e coletivas.

$\mathrm{Na}$ atualidade, os recursos precisam ser o diferencial, devem ter um longo alcance. Existem muitos pedagogos deficientes nesse aspecto, que usam novos recursos, com as mesmas práticas, acreditando e/ou se enganando que está inovando. "Há uma ideia de senso comum, inclusive de muitos pedagogos, de que Pedagogia é o modo como se ensina, o modo de ensinar a matéria, o uso de técnicas de ensino. [...] Trata-se de uma ideia simplista e reducionista" (LIBÂNEO, 2010, p.29). O que pode ser o espelho da formação do seu curso superior.

O curso de graduação em Pedagogia foi, dentre os cursos de graduação em nível superior, um dos que mais sofreu reformulações normativas ao longo de seus anos de existência (GATTI, 2012, p.151). 
Então, porque não vemos muitos efeitos em relação a qualidade, depois que o pedagogo inicia sua prática? Se faz necessário que as políticas de educação sejam direcionadas como uma política de Estado e contínua, sem intervenções de planos de governo individuais.

(...) é a precariedade das políticas formativas, cujas sucessivas mudanças não lograram estabelecer um padrão minimamente consistente de preparação docente para fazer face aos problemas enfrentados pela educação escolar em nosso país (SAVIANI, 2009, p.148).

Qualidades como autoconhecimento, motivação, passam a ser fundamentais para o profissional poder incorporar as técnicas de aprendizado propostas pela atualidade. Dessa forma, cria-se expectativa na qualidade, na formação base desses profissionais, para o crescimento e o desenvolvimento coletivo, englobando todos os pontos contundentes citados acima, nesse processo de integração política.

Esses professores trabalharão com crianças em tenra idade e com a alfabetização, trabalho que exige uma formação delicada, um aprendizado de relações pessoais, pedagógicas, didáticas, motivacionais e de formas de linguagem e comunicação específicas (GATTI, 2012, p.163).

Apenas quando o professor reconhece suas potencialidades e as suas deficiências, tem a plena consciência do que faz assim como os objetivos que pretende alcançar. Muitos são os obstáculos nesse caminho, por vezes, é vital que ele seja reformulado, como citado por Gatti (2012). Essa reformulação, entretanto, exige ser mais do que normativa, necessita ser de reeducação e qualificação profissional por parte do professor universitário.

Dessa forma, para que o profissional queira se aperfeiçoar e aprender a promover um espaço facilitador, é indispensável que ele esteja motivado para isso. Volta-se à questão da importância da motivação quando se trata de formadores de docentes em relação às novas concepções desse processo.

A motivação é um elemento fundamental para a didática. Ela é que define o quanto este formador irá se esforçar para aprender ou modificar sua visão e atitudes. As universidades precisam buscar alternativas para promover o comprometimento através das relações construtivas e de reconhecimento.

Conforme afirma PIMENTA (2003): “[..]a prática educativa é um traço cultural compartilhado que tem relações com o que acontece em outros âmbitos da sociedade e de suas instituições." (p.12) Por isso, é enfatizada a adequação do profissional e aperfeiçoamento para a devida prática educativa da didática, tendo um olhar sobre os desafios que o docente do curso de Pedagogia terá de superar para aproximar sua prática pedagógica com os diferentes contextos em que atuarão os novos docentes nas escolas. 


\section{METODOLOGIA}

Trata-se de pesquisa qualitativa, a partir de revisão bibliográfica.

Minayo, (1994) explica a pesquisa qualitativa enquanto sua capacidade de aprofundamento no campo dos significados, ações e relações humanas, o que permite identificar as relações entre os achados e percepções.

Foram utilizados artigos científicos e livros que referenciavam a discussão sobre a didática na formação docente. Foram pesquisadas a base de dados Scielo, USP e UFSC.

Os conteúdos foram analisados e os resultados descritivos.

\section{CONSIDERAÇÕES FINAIS}

A formação dos professores que atuam no Ensino Superior precisa ser amplamente revista, mesmo quando dispõe de titulações, sendo evidente a necessidade de uma complementação pedagógica para poder exercer plenamente o papel da didática.

Em se tratando disso, foi possível verificar que não são poucos os autores que abordam a didática no ensino superior.

As pesquisas mostraram uma preocupação eminente em promover a formação continuada e/ou pedagógica desses professores.

Todas as questões verificadas apontam para a necessidade de uma complementação didática para que se possa dispor dos recursos necessários para lidar com a diferentes situações do cotidiano escolar, no papel do pedagogo, para que a conclusão do curso de Pedagogia seja um início significante para o pensar da prática educativa nas escolas. 


\section{BIBLIOGRAFIA}

CORDEIRO, Jaime. Didática. $1^{\text {a }}$ ed. São Paulo: Contexto, 2009.

GATTI, Bernardete A. O curso de Licenciatura em Pedagogia: dilemas e convergências. EntreVer, Florianópolis, v.2, n 3, p. 151 - 169, jul./dez. 2012. Disponível em: <https://periodicos.ufsc.br/index.php/EntreVer/article/view/34247. Acesso em: 14 abr. 2020.

LDB: Lei de diretrizes e bases da educação nacional. - 2. ed. - Brasília: Senado Federal, Coordenação de Edições Técnicas, 2018. 58 p.

LIBÂNEO, José Carlos. Didática. São Paulo: Cortez, 1990.

LIBÂNEO, José Carlos. Pedagogia e Pedagogos, para Quê? 12ª Ed. São Paulo: Cortez, 2010.

MINAYO, Maria Cecilia. de S. et al. (Org.). Pesquisa social: teoria, método e criatividade. Petrópolis: Vozes, 1994.

PIMENTA, Selma Garrido. Formação de professores: saberes da docência e identidade do professor. Revista da Faculdade de Educação, São Paulo, v.12, n 2, p. 72-89, jul/dez. 1996. Disponível em: <https//revistas.ussp.br/rfe/article/view/33579/36317. Acesso em: 14 abr. 2020.

PIMENTA, Selma Garrido. (Org.). Saberes pedagógicos e atividade docente. São Paulo: Cortez, 1999

PIMENTA, Selma Garrido; ANASTASIOU, Lea das Graças C. Docência no ensino superior. São Paulo: Cortez, 2003.

RIBAS, Mariana Holzmann. Construindo a competência: processo de formação de professor. São Paulo: Olho d'Água, 2000.

SAVIANI, Demerval. Formação de professores: aspectos históricos e teóricos do problema no contexto brasileiro. Revista Brasileira de Educação. v 14, n 40, p. 143-155, jan./abr. 2009. Disponível em: scielo.br/pdf/rbedu/v14n40a12.pdf

SENGE, Peter. Escolas que aprendem: um guia da Quinta Disciplina para educadores, pais e todos que se interessam pela educação. Peter Senge...[et al.]; tradução Ronaldo Cataldo Costa. Porto Alegre: Artmed, 2005.

VEIGA, Ima Passos Alencastro. (Org.). Didática: ensino e suas relações. Campinas: Papirus, 1996.

ZABALA, Antoni. A prática educativa: como ensinar. Porto Alegre: Artmed, 1998. 